\title{
Blood pressure, ocular perfusion pressure and open-angle glaucoma in patients with systemic hypertension
}

This article was published in the following Dove Press journal:

Clinical Ophthalmology

\author{
Erika Cantor' \\ Fabián Méndez ${ }^{2}$ \\ Carlos Rivera ${ }^{3}$ \\ Andrés Castillo ${ }^{4}$ \\ Alexander Martínez-Blanco ${ }^{5}$ \\ 'Research Institute, Centro Médico \\ Imbanaco, Cali, Colombia; ${ }^{2}$ School \\ of Public Health, GESP Group, \\ Universidad del Valle, Cali, Colombia; \\ ${ }^{3}$ Centro Medico Farallones, Fundación \\ Oftalmológica del Valle, Cali, \\ Colombia; ${ }^{4}$ Department of Biology, \\ Faculty of Natural and Exact Sciences, \\ Universidad del Valle, Cali, Colombia; \\ ${ }^{5}$ Department of Ophtalmology, \\ Universidad del Valle, Research \\ Institute, Centro Médico Imbanaco, \\ Cali, Colombia
}

Background: The aim of the study was to evaluate the relationship between blood pressure (BP), ocular perfusion pressure (OPP) and occurrence of primary open-angle glaucoma (POAG) among patients with systemic hypertension.

Participants and methods: A cross-sectional study of hypertensive patients was conducted in six cities in Colombia. The participants underwent a complete ophthalmological examination. The intraocular pressure measurement was obtained by Goldmann tonometry. The diagnosis of glaucoma was confirmed by visual field and optic nerve photos. Interviews and questionnaires were used to evaluate participants' lifestyle and other health conditions. A multinomial logistic regression was used to assess the relationship between BP, OPP and presence of suspected or confirmed POAG.

Results: A total of 1,272 individuals were included in this study; 131 (10.3\%) were diagnosed with suspected glaucoma and $65(5.1 \%)$ with confirmed glaucoma. High values of diastolic $\mathrm{BP}(>90 \mathrm{mmHg})$ and low values of OPP $(<40 \mathrm{mmHg})$ were associated to an increased risk of confirmed POAG. The type of antihypertensive treatment did not modify these relationships.

Conclusion: This study suggests that there is a close relationship between OPP and confirmed glaucoma in hypertensive patients, providing further evidence of the vascular mechanism in glaucoma pathogenesis.

Keywords: open angle-glaucoma, blood pressure, ocular perfusion pressure, hypertension, ocular blood flow

\section{Introduction}

Glaucoma is considered an optic neuropathy that results in vision loss, and it tends to remain asymptomatic until advanced stages have been reached. It is estimated that over 76 million people will have glaucoma in 2020 increasing to 111.8 million in 2040. Primary open-angle glaucoma (POAG) is the most common form of glaucoma and represents approximately $60 \%-70 \%$ of all cases. ${ }^{1}$

Systemic hypertension has been related to increased intraocular pressure (IOP) and a higher risk of POAG. ${ }^{2}$ Although the physiopathology of glaucoma is still not completely understood, IOP is the main modifiable risk factor due to its direct mechanical effect on the optic nerve head $(\mathrm{ONH})$. Nevertheless, evidence suggests that damage to the optic nerve axons occurs due to microvascular injury and low perfusion. ${ }^{3,4}$ Among vascular factors associated with glaucoma, blood pressure (BP) is the most studied, because it is related to microvascular blood flow and IOP, the two main elements that determine the ocular perfusion pressure (OPP). ${ }^{2}$ Several studies have shown a positive correlation between IOP and $\mathrm{BP},{ }^{5-7}$ which makes difficult the understanding
Correspondence: Erika Cantor Research Institute, Centro Médico Imbanaco, Carrera 38 BIS No 5B2-04, Cali, Colombia

Tel +57 6821000

Email erika.cantor@imbanaco.com.co 
of the complex role that IOP, BP and OPP may have in the prevalence and progression of POAG.

Recently, a bimodal relationship was described between $\mathrm{BP}$ and the risk of glaucoma, indicating that patients with either high or low BP have a higher risk of developing POAG. ${ }^{8,9}$ The OPP could be reduced during the decrease or elevation of BP, and this may result in ischemic injury of the retinal ganglion cells in the absence of an adequate mechanism of autoregulation. ${ }^{2}$ Additionally, in patients with systemic hypertension and glaucoma, vascular dysfunction does not allow the activation of ocular blood flow autoregulation mechanisms, increasing susceptibility to POAG. ${ }^{10-12}$

The objective of this study was to evaluate the relationship between the BP, OPP and POAG in patients with systemic hypertension in a cross-sectional study, the Colombian Glaucoma Study (ECG, from the initials in Spanish).

\section{Participants and methods Design and study population}

ECG is a cross-sectional study of hypertensive and diabetic patients from six cities in Colombia, conducted from September 2014 to October 2015. All participants were selected from the hypertension control programs. At enrollment, individuals were $\geq 50$ years of age and were treated with antihypertensive medications for at least 1 year before the beginning of the study. Subjects with previous intraocular surgery (trauma retinal detachment, complicated cataract surgery, macular degeneration or maculopathy), congenital ocular pathology (eg, coloboma) or severe associated comorbidities (renal failure, congestive heart failure, sleep apnea, autoimmune diseases with biological therapy) were excluded. A total of 1,591 individuals were initially selected, but participants with diagnosis of angle-closure glaucoma and other types of glaucoma $(n=57)$, unconfirmed diagnosis of systemic hypertension $(n=168)$, prior diagnosis of POAG $(n=51)$ and incomplete records $(n=43)$ were excluded. Finally, a total of 1,272 patients were included in the analysis. The Universidad del Valle Review Board approved this study (Approval Code 030-014), and all participants signed informed consent.

The ECG participants underwent a complete ophthalmological examination, including visual acuity measurement, refraction, slit lamp examination, IOP and pachymetry measurement. The IOP measurement was obtained from the average of three values by Goldmann tonometry. The POAG diagnosis was confirmed using visual field (VF) test with the 24-2 Swedish Interactive Threshold Algorithm (Humphry; Carl Zeiss Meditec, Inc) and optic nerve photos; these procedures were only performed in the suspected cases.
Trained glaucomatologists performed the examinations using standardized protocols. Interviews and questionnaires were used to evaluate participants' lifestyle and other health conditions.

\section{Diagnosis of glaucoma}

Suspected and confirmed cases of glaucoma were defined according to the criteria specified by Foster et al. ${ }^{13}$ Confirmed glaucoma was defined as structural and functional evidence of glaucomatous damage in at least one eye that met the following criteria: 1) horizontal or vertical cup-disc ratio $>0.7$ ( 97.5 th percentile), focal glaucomatous disc change (disc hemorrhage, notch of the neuroretinal rim, marked sloping of rim tissue, narrowest remaining rim of 0.1 disc diameter or less), cup/disc asymmetry $>0.2$ (97.5th percentile), associated with a glaucomatous VF defect; 2) horizontal or vertical cup-disc ratio $>0.8$ (99.5th percentile), focal glaucomatous disc change, asymmetry $>0.3$ (99.5th percentile) with absence of functional evidence of glaucomatous damage (if the subject could not satisfactorily complete the VF examination). Cases that did not meet all criteria were classified as suspected glaucoma. In addition, VF defects that were not explained by any other disease, like asymmetry across the horizontal midline, visual defects located in the mid-periphery or clustered in neighboring test points, were defined as compatible with the disease. ${ }^{14}$ Figure 1 shows the VF and optic nerve photos for a confirmed case of POAG.

\section{Measurement of BP and OPP}

BP was measured in sitting position after 5 minutes of rest, using a sphygmomanometer. The cutoff values of BP were defined according to the guidelines for the management of arterial hypertension of European Society of Hypertension. ${ }^{15}$ High BP was defined as systolic BP (SBP) $>140 \mathrm{mmHg}$ or diastolic BP (DBP) >90 mmHg. Low BP was defined as SBP $<90 \mathrm{mmHg}$ and DBP $<60 \mathrm{mmHg}$. Mean arterial BP (MABP) was calculated as $1 / 3 \mathrm{SBP}+2 / 3 \mathrm{DBP}$. The OPP was defined as 2/3 MABP minus IOP, while diastolic OPP (DPP) and systolic OPP (SPP) were defined as DBP or SBP minus IOP, respectively. The highest IOP value between the two eyes was used to calculate OPP.

\section{Statistical analysis}

Suspected and confirmed cases of glaucoma were included in data analysis. The BP values were classified according to the high and low values of SBP and DBP. Comparisons were made using a SBP cutoff value of $110 \mathrm{mmHg}$ due to the small 


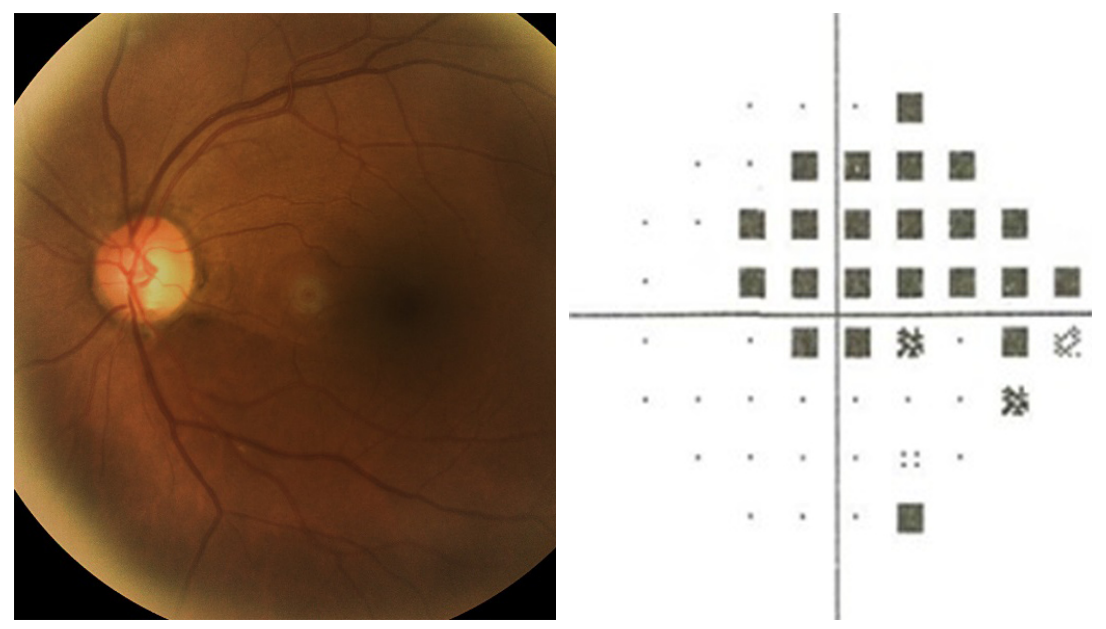

Figure I Example of a case of POAG with inferior retinal nerve fiber layer defect characterized with a superior arcuate defect on VF. Abbreviations: POAG, primary open-angle glaucoma; VF, visual field.

number of participants in the study with SBP $<90 \mathrm{mmHg}$ in this group of hypertensive patients. The SPP, DPP and OPP were categorized into groups of $10 \mathrm{mmHg}$.

The dependent variable had three categories: confirmed glaucoma, suspected glaucoma and no glaucoma, as reference category. Therefore, we applied a multinomial logistic regression model to evaluate the relationships with main independent variables, namely BP and OPP, adjusted by age, sex, diabetes, type of antihypertensive drug used (B-blockers, angiotensin-converting enzyme inhibitors [ACE-I] and angiotensin $\mathrm{II} \mathrm{AT}_{1}$ receptor antagonists [ARBs]), time since diagnosis and IOP. The ORs were calculated with $95 \%$ confidence interval, and goodness-of-fit was evaluated using a likelihood ratio test and the model deviance. All analyses were carried out using Stata 13 (STATA Corp, College Station, TX, USA).

\section{Results}

From 1,272 individuals who met the selection criteria, 131 $(10.3 \%)$ were diagnosed with suspected glaucoma and $65(5.1 \%)$ with confirmed glaucoma. Sixty percent of the individuals had been diagnosed with hypertension for more than 5 years and $32.4 \%$ (412) were diabetic. The percentage of cases with high $\mathrm{SBP}>140 \mathrm{mmHg}$ and $\mathrm{DBP}>90 \mathrm{mmHg}$ were $9.4 \%$ and $5.3 \%$, respectively.

The demographic and clinical characteristics of participants are described in Table 1. Males had a higher risk of confirmed glaucoma than women (OR: 2.2; 95\% CI: 1.3-3.8). No statistically significant relationship was found between age and suspected diagnosis. However, data suggest that the proportion of confirmed POAG was 2-fold higher in the 70-79 years age group (OR: 2.1; 95\% CI: 1.0-4.1) when compared to the youngest age group (50-59 years). The number of persons with diabetes mellitus was lower in the confirmed POAG group (confirmed: $21.5 \%$ vs suspected: $32.8 \%$ ). There was a higher proportion of B-blocker consumption in confirmed POAG (50.0\%). ARB consumption was more common in suspected and no POAG cases. The proportion of IOP $\geq 21 \mathrm{mmHg}$ was $1.7 \%$ among the patients without glaucoma, $5.3 \%$ in the group with suspected POAG and $15.4 \%$ in the one with confirmed POAG. Figure 2 shows the distribution of IOP according to POAG diagnosis.

Table I Demographic and clinical characteristics by presence of POAG

\begin{tabular}{|c|c|c|c|}
\hline & $\begin{array}{l}\text { Confirmed } \\
\text { POAG } \\
\text { N (\%) }\end{array}$ & $\begin{array}{l}\text { Suspected } \\
\text { POAG } \\
\text { N (\%) }\end{array}$ & $\begin{array}{l}\text { No } \\
\text { POAG } \\
\text { N (\%) }\end{array}$ \\
\hline \multicolumn{4}{|l|}{ Age (years) } \\
\hline $50-59$ & 14 (2।.5) & $44(33.6)$ & $322(30.1)$ \\
\hline $60-69$ & $20(30.8)$ & $49(37.4)$ & $422(39.4)$ \\
\hline $70-79$ & $26(40.0)$ & $29(22.1)$ & $26 I(24.4)$ \\
\hline$>80$ & $5(7.7)$ & $9(6.9)$ & $66(6.2)$ \\
\hline \multicolumn{4}{|l|}{ Sex } \\
\hline Female & 31 (47.7) & $89(67.9)$ & 709 (65.9) \\
\hline Male & $34(52.3)$ & $42(32.1)$ & $367(34.1)$ \\
\hline DM & $14(2 \mid .5)$ & $43(32.8)$ & $355(33.0)$ \\
\hline \multicolumn{4}{|l|}{ Antihypertensive drug } \\
\hline B-blockers & $32(50.0)$ & $42(33.6)$ & $413(39.0)$ \\
\hline ACE-I & $22(34.9)$ & $30(24.6)$ & $243(23.5)$ \\
\hline ARBs & $20(31.7)$ & $75(61.5)$ & $514(49.7)$ \\
\hline $\mathrm{DBP}, \mathrm{mmHg}($ mean $\pm \mathrm{SD})$ & $75.9 \pm 13.6$ & $77.1 \pm 10.8$ & $76.9 \pm 10.7$ \\
\hline $\mathrm{SBP}, \mathrm{mmHg}($ mean $\pm \mathrm{SD})$ & $127.3 \pm 18.1$ & $125.8 \pm 15.2$ & $125.8 \pm 15.0$ \\
\hline $\mathrm{IOP}, \mathrm{mmHg}($ mean $\pm \mathrm{SD})$ & $15.8 \pm 5.0$ & $15.3 \pm 2.9$ & $14.3 \pm 2.7$ \\
\hline OPP, $\mathrm{mmHg}($ mean $\pm \mathrm{SD})$ & $46.2 \pm 10.1$ & $46.8 \pm 7.2$ & $47.9 \pm 7.8$ \\
\hline
\end{tabular}

Abbreviations: POAG, primary open-angle glaucoma; DM, diabetes mellitus; ACE-I, angiotensin-converting-enzyme inhibitors; ARBs, angiotensin II AT, receptor antagonists; DBP, diastolic blood pressure; SBP, systolic blood pressure; IOP, intraocular pressure; OPP, ocular perfusion pressure. 


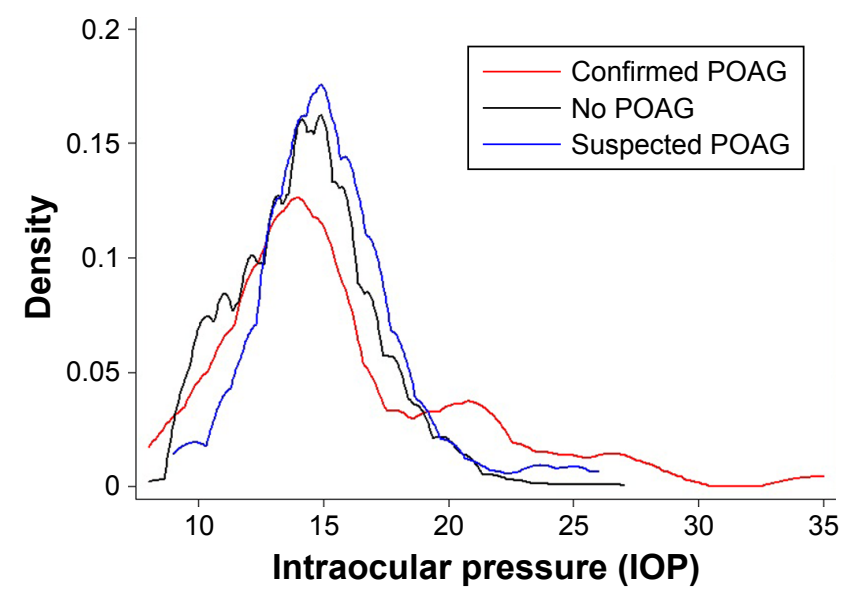

Figure 2 Curve of intraocular pressure according to POAG diagnosis. Abbreviation: POAG, primary open-angle glaucoma.

\section{Relationship between POAG and BP}

After adjusting for age, sex, diabetes, type of antihypertensive drug used and time since diagnosis and IOP, there was no direct relationship between values of SBP or MABP and occurrence of glaucoma. However, an increase of confirmed POAG probability was observed among patients with DBP $>90 \mathrm{mmHg}$; patients with DBP values higher than 90 $\mathrm{mmHg}$ were 2.2 times more likely to have confirmed POAG ( $p$-value: 0.08 ) (Table 2). The type of antihypertensive treatment did not modify the relationship between BP and POAG. In addition, a suggested association between POAG and ARB consumption was not conclusive due to an increase of suspected glaucoma probability (OR: 1.7 [95\% CI: 1.1-2.5]) but a decrease of confirmed glaucoma probability (OR: 0.6 [IC 95\% 0.3-1.0]) with ARB treatment.

\section{Relationship between POAG and OPP}

Low values of OPP and DPP were associated with an increased risk of confirmed POAG. Those with DPP $\leq 50 \mathrm{mmHg}$ were 2.2 times more likely to have confirmed POAG when compared with those with DPP values between 61 and $70 \mathrm{mmHg}$. The relationship between suspected glaucoma and OPP was not statistically significant. We also found that those with OPP of $40 \mathrm{mmHg}$ or less were two times more likely to have confirmed POAG than those with OPP between 41 and $50 \mathrm{mmHg}$. Figure 3 shows a higher percentage of confirmed glaucoma in low $(<40 \mathrm{mmHg}$ ) and high ( $>60 \mathrm{mmHg}$ ) OPP values with a prevalence of $6.4 \%$, decreasing when the OPP was between 41 and $60 \mathrm{mmHg}$. Additionally, high SPP was significantly associated with a higher risk of confirmed glaucoma; those with SPP higher than 130 $\mathrm{mmHg}$ had a higher probability of confirmed POAG than those with SPP between 111 and $120 \mathrm{mmHg}$ (Table 3).

\section{Discussion}

In this program-based study of hypertensive subjects, results suggest that there is no relationship between BP and suspected or confirmed POAG. However, OPP was associated with confirmed glaucoma.

Based on our knowledge, this is the first study that evaluates the cross-sectional relationship between BP, OPP and POAG in hypertensive patients. However, the relationship found with OPP was similar to the findings reported in other populations. ${ }^{9,16,17}$ We did find a similar report, the Rotterdam Eye Study, which is a sub-analysis carried out only in patients undergoing antihypertensive treatment, wherein

Table 2 Distribution and relationship between POAG diagnoses according to the blood pressure level

\begin{tabular}{|c|c|c|c|c|c|}
\hline $\begin{array}{l}\text { Blood } \\
\text { pressure }\end{array}$ & $\begin{array}{l}\text { Confirmed } \\
\text { POAG } \\
\mathrm{N}(\%) \\
\end{array}$ & $\begin{array}{l}\text { Suspected } \\
\text { POAG } \\
\text { N (\%) }\end{array}$ & $\begin{array}{l}\text { No } \\
\text { POAG } \\
\text { N (\%) }\end{array}$ & $\begin{array}{l}\text { OR }(95 \% \mathrm{Cl}) \\
\text { confirmed/ } \\
\text { no GPAA }\end{array}$ & $\begin{array}{l}\text { OR }(95 \% \mathrm{CI}) \\
\text { suspected/ } \\
\text { no GPAA }\end{array}$ \\
\hline \multicolumn{6}{|l|}{$\mathrm{SBP}, \mathrm{mmHg}$} \\
\hline$<110$ & $16(24.6)$ & $29(22.1)$ & $202(18.8)$ & $1.6(0.7-3.3)$ & $1.5(0.8-2.5)$ \\
\hline $111-120$ & $17(26.1)$ & $37(28.2)$ & $355(33.0)$ & 1 & I \\
\hline$|2|-\mid 40$ & $21(32.3)$ & $52(39.7)$ & $424(39.4)$ & $0.9(0.5-1.9)$ & $1.2(0.7-1.9)$ \\
\hline$>140$ & II (16.9) & $13(9.9)$ & $95(8.8)$ & $2.0(0.8-4.5)$ & $1.2(0.6-2.4)$ \\
\hline \multicolumn{6}{|c|}{ DBP, $\mathrm{mmHg}$} \\
\hline$<60$ & II (I6.9) & $19(14.5)$ & $121(11.2)$ & I.3 (0.6-2.7) & $1.6(0.9-2.8)$ \\
\hline $6 I-80$ & $40(61.5)$ & $81(61.8)$ & 735 (68.3) & I & 1 \\
\hline $8 I-90$ & $7(10.8)$ & $27(20.6)$ & $164(15.2)$ & $0.6(0.2-1.6)$ & $1.3(0.8-2.2)$ \\
\hline$>90$ & $7(10.8)$ & $4(3.0)$ & $56(5.2)$ & $2.2(0.9-5.5)^{*}$ & $0.5(0.1-1.5)$ \\
\hline \multicolumn{6}{|c|}{$\mathrm{MABP}, \mathrm{mmHg}$} \\
\hline$<80$ & II (I6.9) & $18(13.7)$ & $117(10.9)$ & $1.2(0.6-2.7)$ & $1.3(0.7-2.5)$ \\
\hline $81-90$ & $20(30.8)$ & $36(27.5)$ & $302(28.1)$ & 1 & I \\
\hline $91-100$ & $18(27.7)$ & $41(31.3)$ & 451 (4I.9) & $0.6(0.3-1.1)$ & $0.7(0.4-I . I)$ \\
\hline$>100$ & $16(24.6)$ & $36(27.5)$ & $206(19.1)$ & $1.0(0.5-2.2)$ & $1.3(0.8-2.1)$ \\
\hline
\end{tabular}

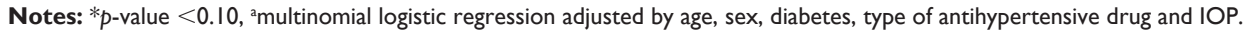

Abbreviations: POAG, primary open-angle glaucoma; SBP, systolic blood pressure; DBP, diastolic blood pressure; MABP, mean blood pressure; IOP, intraocular pressure. 


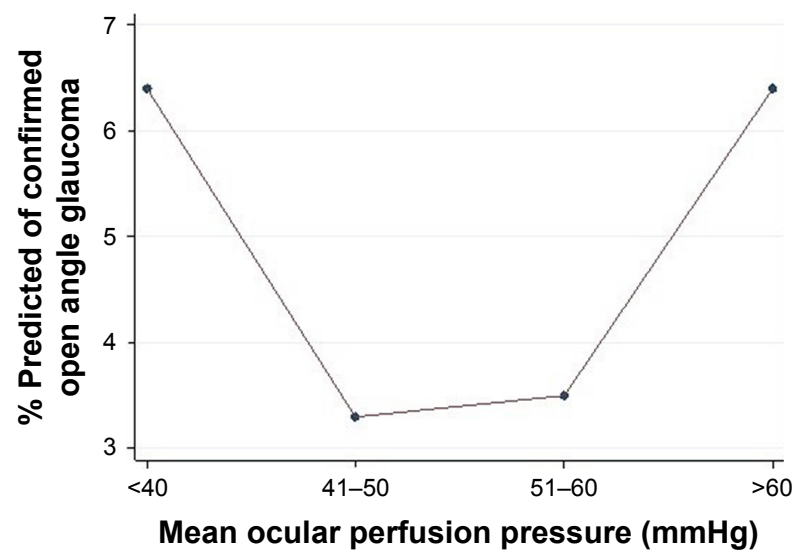

Figure 3 Relationship between OPP and confirmed POAG. Abbreviations: OPP, ocular perfusion pressure; POAG, primary open-angle glaucoma.

an increase of normal tension glaucoma risk in high values of DBP ( $>85 \mathrm{mmHg})$ and an increase of high-tension glaucoma risk in low values of DPP $(<50 \mathrm{mmHg})$ were found. Nevertheless, this study was not conclusive in a relationship between BP and POAG in all population. ${ }^{18}$

Although our data did not reveal a relationship between $\mathrm{BP}$ and POAG, the characteristics of the population included in the analysis could explain this result. In particular, all patients in the study were undergoing hypertensive treatment, which could decrease the probability of hypotension or hypertension events. These events have been associated with the POAG risk in general population. ${ }^{2,8}$ For example, the LALES Study found an increase in POAG risk in high and low values of BP, suggesting that the relationship between
BP and glaucoma is bimodal and " $U$ " shaped. In high values of BP, the risk of development of arteriosclerosis may increase and lead to a reduction of perfusion of the $\mathrm{ONH}$. The events of hypotension when coinciding with an increase of IOP may exacerbate the damage to the ONH due to the reduction of OPP. ${ }^{2,8}$

The relationship found between the OPP and POAG in hypertensive patients is similar to the findings reported in other observational studies. ${ }^{9,16,18-20}$ Therefore, our results suggest that in hypertensive patients, the glaucomatous damage may occur due to the ischemia of the optic nerve or the retinal ganglion cells because of the reduction of the perfusion pressure. These structural changes may induce the development of POAG. Although ocular blood flow is an autoregulated process to ensure the adequate irrigation of ocular tissues, vascular dysfunction processes can disturb it. In patients with systemic hypertension, there have been findings that suggest an alteration in the production of endothelin-1 levels, which is related to the dysfunction processes in the endothelial regulation, reducing the ocular blood flow in patients with glaucoma. ${ }^{10-12}$

On the other hand, there was no relationship between age and diagnosis of suspected POAG. This finding disagrees with those reported in other populations. ${ }^{19,21}$ Confirmed POAG was more frequent among males, which is consistent with the data from Latin population. ${ }^{21}$

The consumption of ARBs was related with a decreased risk of confirmed POAG. However, its consumption was also identified as a risk factor for the presence of suspected POAG.

Table 3 Distribution and relationship between POAG diagnosis according to the OPP

\begin{tabular}{|c|c|c|c|c|c|}
\hline $\begin{array}{l}\text { Ocular } \\
\text { perfusion } \\
\text { pressure } \\
\end{array}$ & $\begin{array}{l}\text { Confirmed } \\
\text { POAG } \\
\mathrm{N}(\%)\end{array}$ & $\begin{array}{l}\text { Suspected } \\
\text { POAG } \\
\text { N (\%) }\end{array}$ & $\begin{array}{l}\text { No } \\
\text { POAG } \\
\text { N (\%) }\end{array}$ & $\begin{array}{l}\text { OR }(95 \% \mathrm{CI}) \\
\text { confirmed } / \\
\text { no GPAA }^{a}\end{array}$ & $\begin{array}{l}\text { OR }(95 \% \mathrm{CI}) \\
\text { suspected } / \\
\text { no } \text { GPAA }^{\mathrm{a}}\end{array}$ \\
\hline \multicolumn{6}{|l|}{ SPP, mmHg } \\
\hline$<100$ & $22(33.8)$ & 31 (23.7) & $229(21.3)$ & I.7 (0.8-3.6) & $0.9(0.6-1.7)$ \\
\hline $101-110$ & $14(2 \mid .5)$ & $36(27.5)$ & $347(32.2)$ & $0.9(0.4-1.9)$ & $0.7(0.4-1.2)$ \\
\hline $111-120$ & $14(2 \mid .5)$ & $42(32.1)$ & $295(27.4)$ & 1 & 1 \\
\hline $121-130$ & $4(6.1)$ & II (8.4) & $120(11.1)$ & $0.7(0.2-2.3)$ & $0.7(0.4-1.5)$ \\
\hline$>130$ & II (16.9) & II (8.4) & $85(7.9)$ & $2.7(I . I-6.4)^{* *}$ & $0.8(0.4-1.7)$ \\
\hline \multicolumn{6}{|l|}{ DPP, $\mathrm{mmHg}$} \\
\hline$<50$ & I4 (2I.5) & $19(14.5)$ & $132(12.3)$ & $2.2(1.0-5.1)^{* *}$ & $1.4(0.8-2.5)$ \\
\hline $51-60$ & $24(36.9)$ & $38(29.0)$ & $334(31.0)$ & $1.7(0.8-3.4)$ & $1.0(0.6-1.6)$ \\
\hline $61-70$ & $15(23.1)$ & 49 (37.4) & $402(37.4)$ & 1 & 1 \\
\hline$>70$ & $12(18.5)$ & $25(19.1)$ & $208(19.3)$ & $1.7(0.8-3.8)$ & $1.0(0.6-1.7)$ \\
\hline \multicolumn{6}{|c|}{ OPP, mmHg } \\
\hline$<40$ & I 8 (27.7) & $23(17.6)$ & $149(13.8)$ & $2.1(I . I-4 . I)^{* *}$ & $1.4(0.8-2.3)$ \\
\hline $4 I-50$ & $26(40.0)$ & $62(47.3)$ & $525(48.8)$ & 1 & 1 \\
\hline $51-60$ & $16(24.6)$ & $43(32.8)$ & $346(32.2)$ & I.I (0.5-2.I) & $1.0(0.6-1.5)$ \\
\hline$>60$ & $5(7.7)$ & $3(3.3)$ & $56(5.2)$ & $1.8(0.6-5.2)$ & $0.1(0.1-1.6)$ \\
\hline
\end{tabular}

Notes: ${ }^{* *} p$-value $<0.05$; ${ }^{a}$ multinomial logistic regression adjusted for age, sex, diabetes, type of antihypertensive drug and IOP.

Abbreviations: POAG, primary open-angle glaucoma; SPP, systolic perfusion pressure; DPP, diastolic perfusion pressure; OPP, ocular perfusion pressure; IOP, intraocular pressure. 
These findings may be considered paradoxical, but it could be explained, in part, by several confounding factors such as the degree of adherence to treatment, time of drug intake and doses received. Although our results suggest a relationship between ARBs and POAG, these have not been documented in the literature. However, other authors have found that the consumption of ACE-I may be related to a higher risk of POAG, and B-blocker consumption could decrease the risk of development of glaucoma. ${ }^{22,23}$

This study used a standardized protocol and a universal definition of glaucoma, which allows the comparison with other studies. Our main limitation is the use of a single measurement of BP, which may be biased by the variability of $\mathrm{BP}$ in patients with hypertension. Therefore, this generates uncertainty about the association found between BP values and POAG. Another limitation is the lack of control characterization of baseline condition of the participants (antihypertensive medication, time of drug intake and doses consumption). This information could help to identify if there are differences between controlled and uncontrolled hypertensive patients.

\section{Conclusion}

The findings of our cross-sectional study in hypertensive patients suggest that there is a close relationship between OPP values and confirmed POAG, providing further evidence of the vascular mechanism in glaucoma pathogenesis. Complementary studies are needed to evaluate the influence of the types of antihypertensive drug in the ocular blood flow.

\section{Acknowledgments}

The authors would like to thank Tecnoquimicas SA for their financial support for this study. The funder had no role in the design of the study and collection, analysis and interpretation of data, and writing the manuscript.

\section{Disclosure}

The authors report no conflicts of interest in this work.

\section{References}

1. Tham YC, Li X, Wong TY, Quigley HA, Aung T, Cheng CY. Global prevalence of glaucoma and projections of glaucoma burden through 2040: a systematic review and meta-analysis. Ophthalmology. 2014; 121(11):2081-2090.

2. Caprioli J, Coleman AL; Blood Flow in Glaucoma Discussion. Blood pressure, perfusion pressure, and glaucoma. Am J Ophthalmol. 2010; 149(5):704-712.

3. Yanagi M, Kawasaki R, Wang JJ, Wong TY, Crowston J, Kiuchi Y. Vascular risk factors in glaucoma: a review. Clin Exp Ophthalmol. 2011;39(3):252-258.

4. Harris A, Werne A, Cantor LB. Vascular abnormalities in glaucoma: from population-based studies to the clinic? Am J Ophthalmol. 2008; 145(4):595-597.
5. Memarzadeh F, Ying-Lai M, Azen SP, Varma R; Los Angeles Latino Eye Study Group. Associations with intraocular pressure in Latinos: the Los Angeles Latino Eye Study. Am J Ophthalmol. 2008;146(1):69-76.

6. Klein BEK, Klein R, Knudtson MD. Intraocular pressure and systemic blood pressure: longitudinal perspective: the Beaver Dam Eye Study. Br J Ophthalmol. 2005;89(3):284-287.

7. Chan MPY, Grossi CM, Khawaja AP, et al; UK Biobank Eye and Vision Consortium. Associations with intraocular pressure in a large cohort: results from the UK Biobank. Ophthalmology. 2016;123(4):771-782.

8. Chung HJ, Hwang HB, Lee NY. The association between primary open-angle glaucoma and blood pressure: two aspects of hypertension and hypotension. Biomed Res Int. 2015;2015:827516.

9. Memarzadeh F, Ying-Lai M, Chung J, Azen SP, Varma R; Los Angeles Latino Eye Study Group. Blood pressure, perfusion pressure, and openangle glaucoma: the Los Angeles Latino Eye Study. Invest Ophthalmol Vis Sci. 2010;51(6):2872-2877.

10. Resch H, Garhofer G, Fuchsjäger-Mayrl G, Hommer A, Schmetterer L. Endothelial dysfunction in glaucoma. Acta Ophthalmol. 2009;87(1): 4-12.

11. He Z, Vingrys AJ, Armitage JA, Bui BV. The role of blood pressure in glaucoma. Clin Exp Optom. 2011;94(2):133-149.

12. Moore D, Harris A, Wudunn D, Kheradiya N, Siesky B. Dysfunctional regulation of ocular blood flow: a risk factor for glaucoma? Clin Ophthalmol. 2008;2(4):849-861.

13. Foster PJ, Buhrmann R, Quigley HA, Johnson GJ. The definition and classification of glaucoma in prevalence surveys. $\mathrm{Br} J$ Ophthalmol. 2002;86(2):238-242.

14. Broadway DC. Visual field testing for glaucoma - a practical guide. Community Eye Health. 2012;25(79-80):66-70.

15. Mancia G, Fagard R, Narkiewicz K, et al. 2013 ESH/ESC guidelines for the management of arterial hypertension: the Task Force for the management of arterial hypertension of the European Society of Hypertension (ESH) and of the European Society of Cardiology (ESC). Eur Heart $J$. 2013;34(28):2159-2219.

16. Zheng Y, Wong TY, Mitchell P, Friedman DS, He M, Aung T. Distribution of ocular perfusion pressure and its relationship with open-angle glaucoma: the singapore malay eye study. Investig Ophthalmol Vis Sci. 2010;51(7):3399-3404.

17. Tham YC, Lim SH, Gupta P, Aung T, Wong TY, Cheng CY. Interrelationship between ocular perfusion pressure, blood pressure, intraocular pressure profiles and primary open-angle glaucoma: the Singapore Epidemiology of Eye Diseases study. Br J Ophthalmol. Epub 2018 Jan 13.

18. Hulsman C, Vingerling JR, Hofman A, Witteman JC, de Jong PT. Blood pressure, arterial stiffness, and open-angle glaucoma: the Rotterdam study. Arch Ophthalmol. 2007;125(6):805-812.

19. Quigley HA, West SK, Rodriguez J, Munoz B, Klein R, Snyder R. The prevalence of glaucoma in a population-based study of Hispanic subjects: proyecto VER. Arch Ophthalmol. 2001;119(12):1819-1826.

20. Leske MC, Wu SY, Hennis A, Honkanen R, Nemesure B; BESs Study Group. Risk factors for incident open-angle glaucoma: the Barbados Eye Studies. Ophthalmology. 2008;115(1):85-93.

21. Doshi V, Ying-Lai M, Azen SP, Varma R; Los Angeles Latino Eye Study Group. Sociodemographic, family history, and lifestyle risk factors for open-angle glaucoma and ocular hypertension. The Los Angeles Latino Eye Study. Ophthalmology. 2008;115(4):639.e2-647.e2.

22. Owen CG, Carey IM, Shah S, et al. Hypotensive medication, statins, and the risk of glaucoma. Invest Ophthalmol Vis Sci. 2010;51(7): 3524-3530.

23. Müskens RP, de Voogd S, Wolfs RC, et al. Systemic antihypertensive medication and incident open-angle glaucoma. Ophthalmology. 2007; 114(12):2221-2226. 
Clinical Ophthalmology

\section{Publish your work in this journal}

Clinical Ophthalmology is an international, peer-reviewed journal covering all subspecialties within ophthalmology. Key topics include: Optometry; Visual science; Pharmacology and drug therapy in eye diseases; Basic Sciences; Primary and Secondary eye care; Patien Safety and Quality of Care Improvements. This journal is indexed on

Submit your manuscript here: http://www.dovepress.com/clinical-ophthalmology-journal

PubMed Central and CAS, and is the official journal of The Society of Clinical Ophthalmology (SCO). The manuscript management system is completely online and includes a very quick and fair peer-review system, which is all easy to use. Visit http://www.dovepress.com/ testimonials.php to read real quotes from published authors. 